\title{
Maternal urinary 2-hydroxynaphthalene and birth outcomes in Taiyuan, China
}

\author{
Jisheng Nie ${ }^{1,2^{*}+}$, Jinyu $\mathrm{Li}^{1 \dagger}$, Lin Cheng ${ }^{1}$, Yanning $\mathrm{Li}^{1}$, Yunjun Deng ${ }^{1}$, Zhiwei Yan', Lei Duan ${ }^{1}$, Qiao Niu', \\ Frederica Perera ${ }^{2}$ and Deliang Tang ${ }^{1,2^{*}}$
}

\begin{abstract}
Background: Naphthalene is the simplest polycyclic aromatic hydrocarbon (PAH). It is easily emitted into the atmosphere, posing a significant risk to human health. However, limited studies have described the impact of naphthalene exposure on birth outcomes. In this study, we investigated the association between the maternal urinary metabolites of naphthalene, 2-hydroxynaphthalene (2-OH NAP), and birth outcomes.

Method: In the present study, four urinary PAH metabolites were measured in 263 pregnant women during late pregnancy. Multiple linear regression analysis was used to analyze the relationship between the concentrations of 2-OH NAP and birth outcomes, and restricted cubic spline models were further used to examine the shapes of the dose-response association.

Result: General linear models showed that prenatal urinary 2-OH NAP was associated with lower birth weight (BW) $(-4.38 \%$ for the high vs. low exposure group of 2-OH NAP; $p$ for trend $=0.049)$ and higher cephalization index (Cl) $(4.30 \%$ for the high vs. low exposure group of 2-OH NAP; $p$ for trend $=0.038)$. These associations were linear and significant when 2-OH NAP was modeled as a continuous variable in restricted cubic spline models ( $P$ linear $=0.0293$ for $2-\mathrm{OH}$ NAP and $\mathrm{BW} ; \mathrm{P}_{\text {linear }}=0.0326$ for 2-OH NAP and $\mathrm{Cl}$ ). Multiple linear regression data indicated that each 1 In-unit increase in 2-OH NAP was significantly associated with a $2.09 \mathrm{~g} / \mathrm{cm}$ increase in the $\mathrm{Cl}$. The associations among $2-\mathrm{OH}$ NAP, BW, and Cl were also observed in a subset of participants residing close to arterial traffic.

Conclusion: Our data indicated that prenatal exposure to naphthalene had an adverse effect on fetal birth outcomes, especially the brain development index. Reduced exposure to naphthalene may improve newborn health outcomes. In Taiyuan, naphthalene may result from traffic pollution.
\end{abstract}

Keywords: Naphthalene, 2-hydroxynaphthalene, Birth outcomes, Polycyclic aromatic hydrocarbons, Prenatal exposure

\section{Background}

Naphthalene, the simplest polycyclic aromatic hydrocarbon (PAH), is a natural constituent of petroleum and a product of incomplete combustion of organic materials and petroleum products. Naphthalene is detected in cigarette smoke, in automobile exhaust and during combustion of petroleum products [1]. It is easily emitted into the atmosphere in gaseous form and contributes to air pollution. Most studies address the effect of five- to six- ring PAHs on human health due to the contaminants related to genotoxicity, carcinogenic capability,

\footnotetext{
* Correspondence: niejisheng@sxmu.edu.cn; dt14@cumc.columbia.edu ${ }^{1}$ Department of Occupational and Environmental Health, School of Public Health, Shanxi Medical University, Xinjiannan Road 56, Taiyuan 030001, China Full list of author information is available at the end of the article
}

and the specificity of chemical structure. The effects of naphthalene on human health are often overlooked because of the diminished toxicity detected in a lower dose range for this $\mathrm{PAH}$.

Studies demonstrate that exposure to naphthalene can destroy red blood cells and cause confusion, nausea, vomiting, and jaundice $[2,3]$. The US national toxicology program notes that naphthalene exposure can increase the incidence of cancer [4]. Another study also suggests that naphthalene levels should be thoroughly monitored in industrial cities with high levels of PAH [5]. In China, the use of naphthalene in mothballs is forbidden due to its potential toxicity on human health [6]. The above information suggests that the toxicity of naphthalene to human health should not be overlooked.

(c) The Author(s). 2018 Open Access This article is distributed under the terms of the Creative Commons Attribution 4.0 International License (http://creativecommons.org/licenses/by/4.0/), which permits unrestricted use, distribution, and reproduction in any medium, provided you give appropriate credit to the original author(s) and the source, provide a link to the Creative Commons license, and indicate if changes were made. The Creative Commons Public Domain Dedication waiver (http://creativecommons.org/publicdomain/zero/1.0/) applies to the data made available in this article, unless otherwise stated. 
The fetus is more susceptible to toxicological consequences of environmental toxicants because of its physiologic immaturity, weak capability to detoxify toxic chemicals, and deficient immune system responses $[7,8]$. Recent studies have also revealed the presence of naphthalene in placental tissue and indicated that naphthalene can easily cross the placental barrier $[9,10]$. Therefore, the impact of prenatal naphthalene exposure on offspring health should be focused.

Birth outcomes are objective and visual indicators that can reveal the nutritional and health status of infants and fetuses and predict the possibility and risks of adulthood diseases [11-15]. This association of birth outcomes with PAH metabolites has been reported recently. Polanska et al. [16] detected a link between the sum of hydroxyphenanthrene levels and the higher cephalization index (CI). The relationship between 1-hydroxypyrene (1-OH PYR) and birth outcomes has also been investigated in previous studies $[9,17,18]$. However, the association between naphthalene exposure and birth outcomes has rarely been tested in epidemiological studies. In the in vivo experiment, pregnant rats administered oral naphthalene had lower weights and fewer pups per litter than control rats $[19,20]$. Taiyuan, China, is an industrialized city with relatively high levels of $\mathrm{PAH}$ in air pollution attributed to multiple sources, especially coal burning for industrial purposes and automobile exhaust [21]. The emission load of naphthalene is also the highest among 16 PAHs identified by the US EPA [22]. Therefore, using the Taiyuan Mother and Child Cohort Study data, we aimed to explore the association between 2-OH NAP and birth outcomes in newborns and provide guidance for reducing exposure to hazardous pollutants.

\section{Subjects and methods Study population}

Pregnant women who waited for delivery during the third trimester of pregnancy ( $\geq 35$ weeks) in the Sixth Hospital of Shanxi Medical University and The Eighth People's Hospital of Taiyuan were invited to participate in the Taiyuan Mother and Child Cohort Study. Pregnant women who had resided in Taiyuan for at least 1 year, were nonsmokers, were $\geq 18$ years of age, and had a single gestational viable fetus were considered eligible for participation in the cohort study. A total of 287 pregnant women were included in the study. According to self-reported and medical record data, 17 subjects who had a chronic disease were excluded from the study. Urine samples and cord blood were collected for analysis from the 263 pregnant women included in the analysis. Prior to enrolling subjects, all participants gave written informed consent and the study was approved by the Research Ethics Committee of Shanxi Medical University.

\section{Personal interview questionnaire}

Immediately following consent to participate, participants were asked to complete a validated questionnaire supervised by a trained interviewer during the perinatal period. The questionnaire collected maternal demographic information (place of residence, duration of residence, age, health condition, education, occupation, and socioeconomic status), characteristics of the newborns (birth outcomes, vital signs and condition during delivery), and maternal individual behaviors and lifestyles (active and passive smoking, frequency of eating fried, broiled and barbecued meat and consumption of alcohol during the whole period of pregnancy). Passive smoking refers to self-reported exposure to tobacco smoke more than 15 min every day [23]. The definition of arterial road was consistent with that in the code for transport planning on urban road, which includes $40-60 \mathrm{~km} / \mathrm{h}$ speed, more than 4 automobile lanes, 3.5-m lane width, and a separation zone [24]. The determination of $35 \mathrm{~m}$ as a cutoff point was based on a previous study [25]. Within a 35- $\mathrm{m}$ distance from the residence to the arterial road, the level of heavy metals in the roadside soil gradually increases with increasing distance, and beyond $35 \mathrm{~m}$, the level of heavy metal is relatively stable. Spouse demographic information was also collected. To ensure the quality of the questionnaire, personal interview time was no less than 45 minutes.

\section{Biological sample collection and analysis}

Urine samples $(30-50 \mathrm{~mL})$ were collected from the pregnant women during the last antenatal physical examination. The urinary samples were transported to the laboratory immediately, repackaged into 5 - $\mathrm{mL}$ cryogenic vials, and then stored at $-80^{\circ} \mathrm{C}$ until chemical analyses. Umbilical cord blood was drawn immediately after delivery into whole blood tubes with spray-coated EDTA (BD, Franklin Lakes, NJ, USA) and then repackaged into 1 -mL cryogenic vials and stored at $-80{ }^{\circ} \mathrm{C}$ until chemical analyses.

The PAH metabolites measured in the present study included 2-hydroxynaphthalene (2-OH NAP), 2-hydroxyfluene (2-OH FLU), 9-hydroxyphenanthrene (9-OH PHE), and 1-hydroxypyrene (1-OH PYR). The four PAH metabolites were measured using high-performance liquid chromatography with a fluorescence detector (HPLC-FLD (Shimadzu, Kyoto, Japan)) as described previously [26, 27]. Briefly, $5 \mathrm{~mL}$ of thawed urine sample was hydrolyzed with $25 \mu \mathrm{L} \beta$-glucuronidase, loaded onto a Sep-Pak $\mathrm{C}_{18}$ (6cc, $500 \mathrm{mg}$ ) cartridge (Waters, Mil-ford, MA, USA) and condensed by dry nitrogen purge to obtain a $0.5-\mathrm{mL}$ extract. The extract was then analyzed using HPLC-FLD to determine 2-OH NAP, 2-OH FLU, 9-OH PHE and 1-OH PYR levels. The details of the separation condition and program were as follows. Four PAH 
metabolites were separated using a $\mathrm{C}_{18}$ column, an oven temperature of $35^{\circ} \mathrm{C}$, manual injection of $20 \mu \mathrm{L}$ and flow of $1.0 \mathrm{~mL} / \mathrm{min}$, with a gradient elution program using methanol and water (methanol: $60 \%$ during the first 10 $\mathrm{min}$, increasing to $70 \%$ in the following $15 \mathrm{~min}$ to $30 \mathrm{~min}$, then returning to $60 \%$ after $35 \mathrm{~min})$. The wavelength excitation (Ex) and emission (Em) of the fluorescence detector were as follows: (1) 2-OH NAP (227/355), (2) 2-OH FLU (275/330), (3) 9-OH PHE (255/385), and (4) 1-OH PYR $(242 / 385)$. The calibration standards of 2-OH NAP, 2-OH FLU, 9-OH PHE and 1-OH PYR were purchased from Sigma-Aldrich Co. (USA). $\beta$-Glucuronidase (glucuronidase activity $\geq 100,000$ units $/ \mathrm{mL}$ ) was obtained from Roche Co. (Germany); sodium acetate and methanol (HPLC Grade) were obtained from Sigma-Aldrich Co. (USA) and Fisher Scientific Co. (USA), respectively. The limit of detection (LOD) was determined as the lowest calibration standard at which analytes provided a signal-to-noise ratio $(\mathrm{S} / \mathrm{N})$ of 3 . The linearity (expressed as $\mathrm{R}^{2}$ ), LOD, precision (expressed as relative standard deviation (RSD)), and mean recovery rate were $0.9998-1,0.01-0.05 \mu \mathrm{g} / \mathrm{L}, 0.17-$ $2.4 \%$, and $83.75-100.50 \%$, respectively. Reagent blanks and urine samples were analyzed, and none of the PAH metabolites were detected in the blanks, indicating that the experimental process did not introduce contamination. To control for urine dilution, we adjusted PAH metabolite concentrations for urine creatinine levels, which were detected using alkaline picrate $[26,27]$ and quantified by spectrophotometry (SpectraMAx M2, Molecular Devices, USA) at a wavelength of $520 \mathrm{~nm}$.

Urinary phenol was measured using a Gas Chromatographic with Hydrogen Flame Ionization detector (GC, Shimadzu, Kyoto, Japan) according to Health Industry Standards of the People's Republic of China WS/T 501996 [28]. Briefly, the urine sample was heated with hydrochloric acid to hydrolyze the phenol and extracted with diethyl ether. Urinary phenol was separated from the normal human metabolite p-cresol by an FFAP column and was detected by a Hydrogen Flame Ionization detector. Then, according to the peak height, we used the external standard method to quantify the urinary phenol levels.

The cord blood lead measurement was performed with a PinAAcle900Z atomizer absorption spectrophotometer coupled to a THGA graphite furnace and a programmable sample dispenser (PerkinElmer Company, MA, USA), as described previously [29]. The LOD was $0.1 \mu \mathrm{g} / \mathrm{L}$. All of the cord blood lead levels in our study were above the LOD. Regular quality control procedures included instrument calibration, procedural blanks, replicates, and certified reference materials to ensure the accuracy of measurement. The standard reference materials (Contox; Kaulson Laboratories, Inc., NJ, USA) were used in the daily calibration. All biological samples were analyzed by Shanxi Medical University.

\section{Anthropometric measurement of the newborn}

We summarized information on birth outcomes from maternal and newborn medical records. The anthropometric indicators of the newborn in the present analyses included birth weight (BW) (in grams), birth length (BL), birth head circumference (BHC) (in centimeters), and two growth proportionality indices: ponderal index (PI) and CI. The PI $\left[\mathrm{BW}(\mathrm{g}) /(\mathrm{BL}(\mathrm{cm}))^{3} \times 10^{2}\right]$ is similar to body mass index and is most commonly used in pediatrics [30]. The CI $\left[\mathrm{BHC}(\mathrm{cm}) / \mathrm{BW}(\mathrm{g}) \times 10^{4}\right]$ is a validated predictive indicator of intrauterine growth retardation that affects fetal brain development [31]. A higher CI reflects a greater degree of brain vulnerability and more severe clinical pathology as well as the likelihood of cerebral palsy and severe psychomotor retardation [32].

\section{Statistical analysis}

The collected data were analyzed using SPSS 16.0 (SPSS Inc., Chicago, IL, USA) and SAS 9.4 (SAS Institute, Inc., Cary, NC). A bilateral $p$-value less than 0.05 was considered statistically significant. Continuous variables are expressed as the mean \pm standard deviation (SD) or median and interquartile range (IQR). Categorical variables are presented as numbers and frequencies (\%). Natural $\log$ transformation was applied to all the exposure metrics (2-OH NAP, 2-OH FLU, 9-OH PHE, and 1-OH PYR) to correct skewed distributions. The concentration of each PAH metabolite below the LOD was assigned a value corresponding to one-half the LOD. Spearman correlation analysis was used to evaluate the association between PAH metabolites and birth outcomes. General linear models and restrict cubic spline models were used to explore the dose-response association between $\mathrm{PAH}$ metabolites and birth outcomes after adjusting for potential confounders. Multiple linear regressions were used to estimate the effect of PAH exposure on birth outcomes. To assess the presence of collinearity and independence among the covariates, we ran the variance inflation factor (VIF), tolerance, and Durbin-Watson (DW) test on all linear regression models [9, 33-35]. The VIF value of each variable was far less than 10 , the tolerance value of each variable was more than 0.1 , and the DW value also met the requirements, indicating that there was no strong collinearity problem in any independent variable (Additional file 1: Table S1 and Table S2). Tikhonov regularization was also used to eliminate the effect of multicollinearity on regression models and to validate the association between PAH metabolites and birth outcomes. Power analysis was used to evaluate the power of sample size. Potential confounding factors [maternal age, maternal BMI, parity, gender of newborn, gestational age, eating grilled meat, passive smoking] were included in the models based on previous literature. 
Considering that benzene and lead were also the main components of traffic-related pollutants, we further adjusted for urinary phenol and cord blood lead levels in regression models.

\section{Results}

Table 1 shows the baseline characteristics of 263 mother-newborn pairs analyzed in the present study. The age of pregnant women ranged from 19 to 40. More than half of pregnant women were passive smokers (57.4\%) and reported their residence adjoining arterial traffic $(<35 \mathrm{~m})(57.0 \%)$. The number of female babies was lower than the number of male babies in the population (44.9 and 55.1\%, respectively). Most newborns were registered as a first child (72.6\%). The BW, BL, $\mathrm{BHC}, \mathrm{PI}$ and $\mathrm{CI}$ of infants at the time of delivery were not significantly different between females and males.

Table 1 Profiles of the mother-newborn pairs in this study $(n=263)$

\begin{tabular}{|c|c|}
\hline Variables & Mean \pm SD or $N(\%)$ \\
\hline \multicolumn{2}{|l|}{ Maternal characteristics } \\
\hline Age (years) & $27.3 \pm 4.2$ \\
\hline BMI $\left(\mathrm{kg} / \mathrm{m}^{2}\right)$ & $27.7 \pm 3.2$ \\
\hline Parity $(n>1)$ & $72(27.4 \%)$ \\
\hline \multicolumn{2}{|l|}{ Education status } \\
\hline Middle school and below & $84(31.9 \%)$ \\
\hline High school & $62(23.6 \%)$ \\
\hline College and above & $117(44.5 \%)$ \\
\hline \multicolumn{2}{|l|}{ aEconomic status } \\
\hline Below poverty line & $61(23.2 \%)$ \\
\hline Above poverty line & $202(76.8 \%)$ \\
\hline Eating grilled meat (yes) & $146(55.5 \%)$ \\
\hline Passive smoking (yes) & $151(57.4 \%)$ \\
\hline Heating type (self-provided) & $65(24.7 \%)$ \\
\hline Cooking during pregnancy (yes) & $117(44.5 \%)$ \\
\hline${ }^{*}$ Arterial traffic $(<35 \mathrm{~m})$ & $150(57.0 \%)$ \\
\hline bUrinary phenol ( $\mu \mathrm{g} / \mathrm{mL})$ & $3.7(1.7,8.7)$ \\
\hline \multicolumn{2}{|l|}{ Newborn characteristics } \\
\hline Gender (female) & $118(44.9 \%)$ \\
\hline Birth weight (BW) (g) & $3397.2 \pm 429.8$ \\
\hline Birth length (BL) (cm) & $50.7 \pm 1.9$ \\
\hline Birth head circumference (BHC) (cm) & $34.4 \pm 1.4$ \\
\hline Gestational age (days) & $278.7 \pm 7.6$ \\
\hline Ponderal index (PI) $\left(\mathrm{g} / \mathrm{cm}^{3}\right)$ & $2.6 \pm 0.3$ \\
\hline Cephalization index $(\mathrm{Cl})(\mathrm{g} / \mathrm{cm})$ & $102.7 \pm 11.2$ \\
\hline${ }^{\mathrm{b} C}$ ord blood lead (ng/mL) & $24.7(19.6,31.2)$ \\
\hline
\end{tabular}

Table 2 demonstrates the urinary concentration distribution of four PAH metabolites. To compare with similar studies, we show the creatinine-corrected concentrations in this table. The median and interquartile range (IQR) of PAH metabolites, including 2-OH NAP, 2-OH FLU, 9-OH PHE, 1-OH PYR and $5 \mathrm{OH}-\mathrm{PAH}$, in maternal urine were $6.34 \quad(4.03-9.41), \quad 3.47 \quad(2.23-5.40), 2.88$ (1.46-4.68), 1.83 (0.90-3.03), and 14.81 (10.40-22.07) $\mu \mathrm{g} / \mathrm{g} \mathrm{Cr}$, respectively. The median value of $2-\mathrm{OH}$ NAP was the highest $(6.34 \mu \mathrm{g} / \mathrm{g} \mathrm{Cr})$ in this study. There were no direct data in our study about atmospheric PAH levels in Taiyuan. Jing JQ et al. [22] showed that the highest emission load was naphthalene in Taiyuan among 16 PAHs identified by the US EPA, with a 39.18\% contribution rate (Additional file 1: Table S3). The PAH levels in the emission load were consistent with maternal urinary PAH metabolite levels. There was a seasonal difference with respect to $\mathrm{PAH}$ metabolite levels in maternal urine. The 2-OH NAP level is relatively high in January and February, while the other three PAH metabolites were basically unchanged (Additional file 1: Figure S1). Spearman correlation analysis showed that there were positive correlations among PAH metabolites. Maternal urinary 2-OH NAP was significantly associated with BW $(r=-0.15)$ and the PI $(r=-0.13)$ with $P$-values of $<0.05$ for both. A similar pattern was observed for 2-OH FLU with an $\mathrm{r}$ $(P$-values $)$ of $-0.15 \quad(<0.05)$ and $-0.18 \quad(<0.05)$ for $\mathrm{BW}$ and the PI, respectively. In contrast, maternal urinary 2-OH NAP and 2-OH FLU showed significant positive relationships with the CI $(r=0.17 ; r=0.15)$, with P-values $<0.05$ for both. The 9-OH PHE and 1-OH PRY levels were inversely associated with the PI $(r=-0.14 ; r=-0.18)$ (Additional file 1: Table S4).

The scatter plots showed a linear association between $2-\mathrm{OH}$ NAP and the $\mathrm{CI}$, indicating that $10 \%$ of the overall variation depends on 2-OH NAP (Fig. 1). According to the detected concentrations of 2-OH NAP, 2-OH FLU, 9-OH PHE, and 1-OH PYR in maternal urine samples, we classified subjects into the low exposure group (the 1 st IQR), middle exposure group (the 2nd and 3rd IQR), or high exposure group (the 4th IQR). The adjusted means of birth outcomes across exposure groups are

Table 2 Urinary creatinine-corrected concentrations of the four PAH metabolites in mothers $(n=263(\mu \mathrm{g} / \mathrm{g} \mathrm{Cr}))$

\begin{tabular}{llllll}
\hline Exposure metric & P25 & P50 & P75 & GM & Range \\
\hline 2-OH NAP & 4.03 & 6.34 & 9.41 & 5.89 & $0.59-91.02$ \\
2-OH FLU & 2.23 & 3.47 & 5.40 & 3.34 & $0.35-23.56$ \\
9-OH PHE & 1.46 & 2.88 & 4.68 & 2.62 & $0.35-26.24$ \\
1-OH PYR & 0.90 & 1.83 & 3.03 & 1.60 & $0.18-14.42$ \\
$\Sigma$ OH PAH & 10.40 & 14.81 & 22.07 & 14.82 & $2.83-104.22$
\end{tabular}

$\Sigma \mathrm{OH}$ PAH: the sum of four metabolites of PAH 


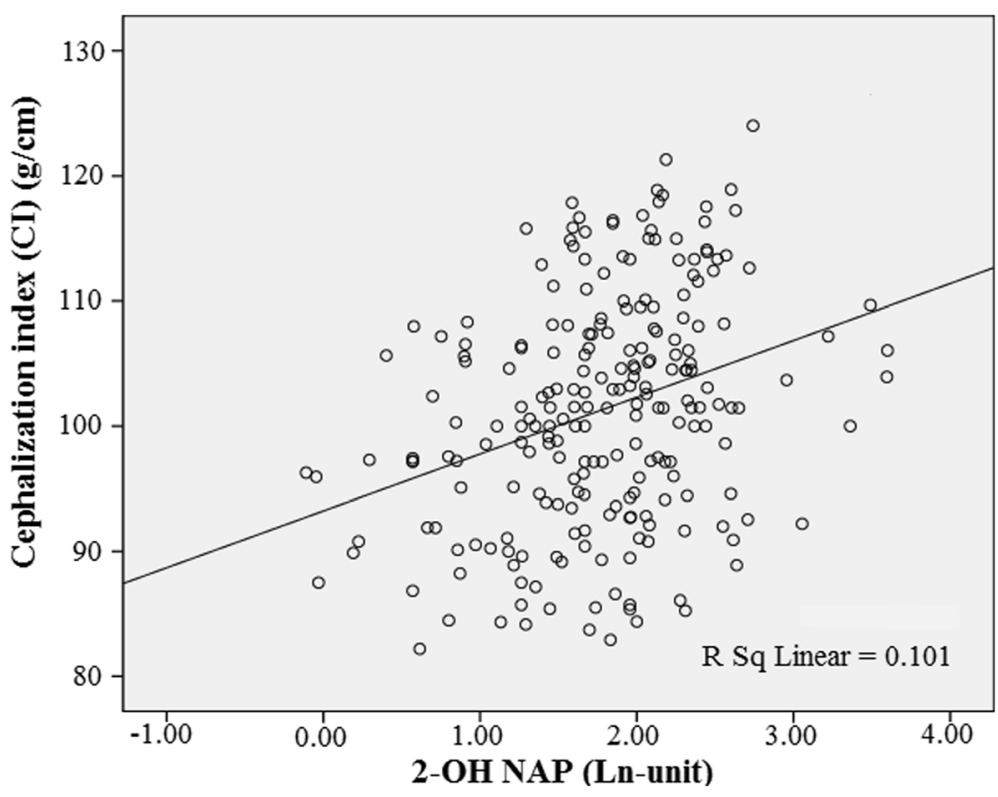

Fig. 1 Scatter plots between natural log transformation creatinine-corrected urinary 2-OH NAP (Ln 2-OH NAP) concentration and the cephalization index (Cl)

presented in Table 3. General linear model data showed statistically significant differences among the low, middle and high exposure groups with respect to BW and the CI stratified by maternal urinary 2-OH NAP after adjusting for potential confounders. A linear test showed that a higher 2-OH NAP level in maternal urine was associated with a lower newborn BW ( $\mathrm{p}$ for trend $=0.049$ ) and a higher $\mathrm{CI}$ ( $\mathrm{p}$ for trend $=0.038$ ) after adjusting for parity, maternal BMI, maternal age, gender of newborn, gestational age, eating grilled meat, passive smoking, and 2-OH FLU, 9-OH PHE, 1-OHPYR, urinary phenol, and cord blood lead levels. The 2-OH FLU was also associated with a higher CI ( $\mathrm{p}$ for trend $=0.027$ ). However, there were no significant trends among the compared levels of other birth outcomes in subjects stratified by urinary levels of 9-OH PHE and 1-OH PYR. Furthermore, the dose-response associations of urinary 2-OH NAP and 2-OH FLU with decreased BW and increased CI were confirmed in the restricted cubic spline models. The results from the general linear model were consistent with the results from restricted cubic spline models (Fig. 2). The $P$-value for linear association was less than 0.05. The different models used to test the association between birth outcomes and urine levels of PAH metabolites are presented in Table 4. We consistently observed that 2-OH NAP was associated with a higher CI in different models. The $\mathrm{CI}$ was positively associated with 2-OH NAP $(\beta=2.09, p=0.035)$. These data suggested that naphthalene may serve as the primary PAH metabolite associated with the adverse effects of PAH, including decreased BW and increased CI. After eliminating
Table 3 Birth outcomes of newborns stratified by the four maternal urinary $\mathrm{PAH}$ metabolites

\begin{tabular}{|c|c|c|c|c|c|c|}
\hline Group & $\mathrm{N}$ & BW & $B L$ & $\mathrm{BHC}$ & $\mathrm{Pl}$ & $\mathrm{Cl}$ \\
\hline \multicolumn{7}{|l|}{$2-\mathrm{OH}$ NAP $(\mu \mathrm{g} / \mathrm{g} \mathrm{Cr})$} \\
\hline Low $(<4.03)$ & 67 & 3484.7 & 50.9 & 34.4 & 2.6 & 100.1 \\
\hline Middle (4.03-9.41) & 130 & 3385.1 & 50.6 & 34.5 & 2.6 & 103.3 \\
\hline High $(\geq 9.41)$ & 66 & 3332.2 & 50.5 & 34.3 & 2.6 & 104.4 \\
\hline$P$ for trend & & 0.049 & 0.301 & 0.525 & 0.305 & 0.038 \\
\hline \multicolumn{7}{|l|}{ 2-OH FLU ( $\mu \mathrm{g} / \mathrm{g} \mathrm{Cr})$} \\
\hline Low $(<2.23)$ & 66 & 3488.4 & 51.0 & 34.4 & 2.6 & 99.9 \\
\hline Middle (2.23-5.40) & 131 & 3396.0 & 50.7 & 34.5 & 2.6 & 102.8 \\
\hline High ( $\geq 5.40$ ) & 66 & 3308.3 & 50.3 & 34.4 & 2.6 & 105.5 \\
\hline$P$ for trend & & 0.060 & 0.118 & 0.923 & 0.805 & 0.027 \\
\hline \multicolumn{7}{|l|}{ 9-OH PHE ( $\mu \mathrm{g} / \mathrm{g} \mathrm{Cr})$} \\
\hline $\operatorname{Low}(<1.46)$ & 66 & 3372.6 & 50.6 & 34.5 & 2.6 & 103.3 \\
\hline Middle (1.46-4.68) & 131 & 3392.1 & 50.8 & 34.4 & 2.6 & 102.7 \\
\hline High ( $\geq 4.68)$ & 66 & 3431.9 & 50.5 & 34.4 & 2.7 & 102.3 \\
\hline$P$ for trend & & 0.567 & 0.699 & 0.866 & 0.404 & 0.708 \\
\hline \multicolumn{7}{|l|}{ 1-OH PYR ( $\mu \mathrm{g} / \mathrm{g} \mathrm{Cr})$} \\
\hline Low $(<0.90)$ & 66 & 3401.6 & 50.1 & 34.5 & 2.7 & 102.9 \\
\hline Middle (0.90-3.03) & 131 & 3362.2 & 50.8 & 34.4 & 2.6 & 103.7 \\
\hline High ( $\geq 3.03$ ) & 66 & 3462.2 & 50.9 & 34.4 & 2.6 & 100.8 \\
\hline $\mathrm{P}$ for trend & & 0.550 & 0.108 & 0.887 & 0.218 & 0.439 \\
\hline
\end{tabular}

Adjusted by parity, maternal BMI, maternal age, gender of newborn, gestational age, eating grilled meat, passive smoking, and levels of the other three PAH metabolites, urinary phenol, and cord blood lead. $P$-value $<0.05$ was marked in bold 


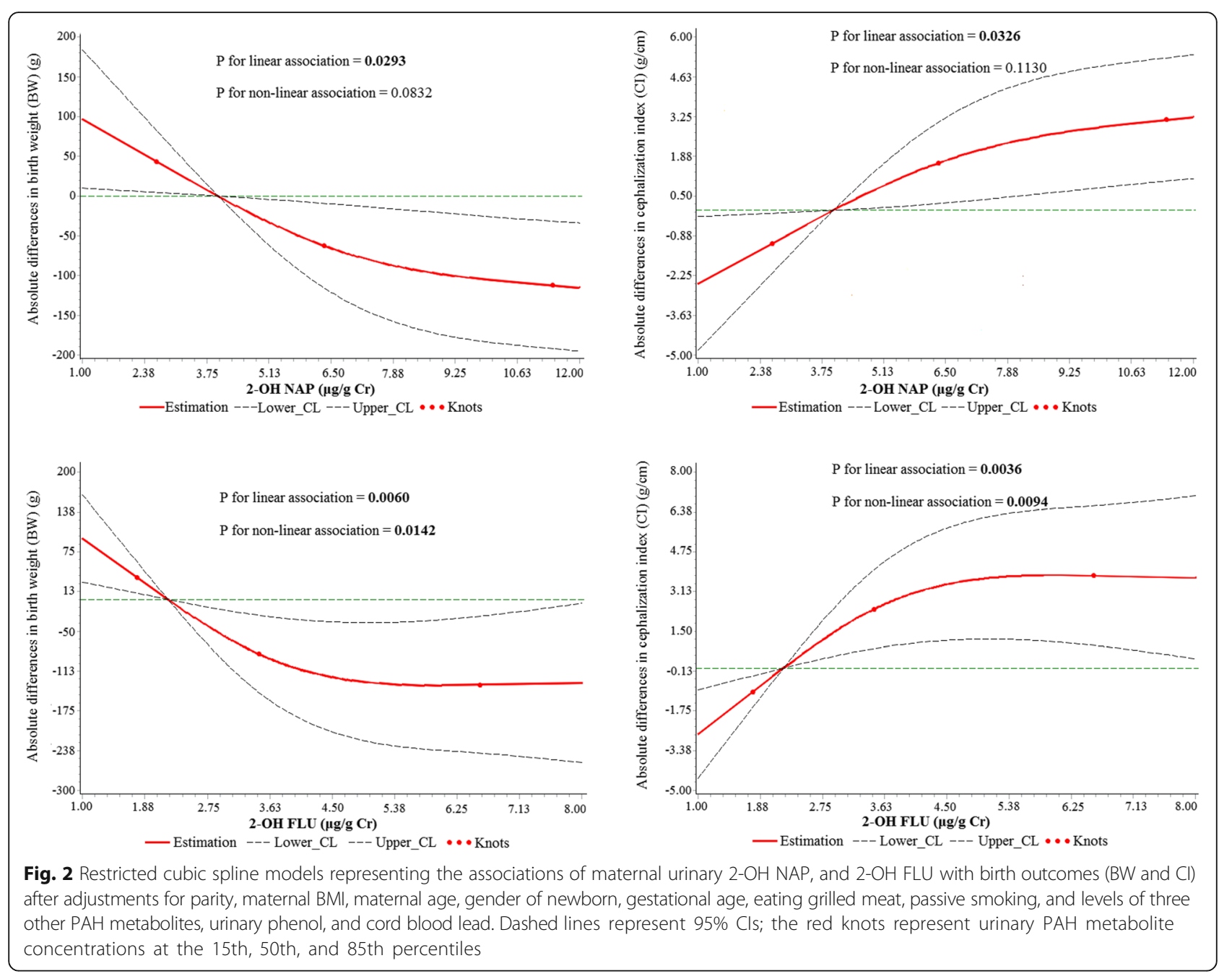

the effect of multicollinearity, Tikhonov regularization also concluded that 2-OH NAP was positively associated with CI $(\beta=1.80, p=0.035)$ (Additional file 1: Table S5, Figure S2, and Figure S3). Furthermore, in model 4, $1-\mathrm{OH}$ PYR was negatively associated with PI $(\beta=-0.09$, $p=0.004)$. However, the association of $2-\mathrm{OH}$ FLU and 9-OH PHE with birth outcomes disappeared after adjustments for parity, maternal BMI, maternal age, gender of newborn, gestational age, eating grilled meat, passive smoking, and levels of urinary phenol, cord blood lead, and the other three PAH metabolites. Additionally, maternal BMI and gestational age were correlated with birth outcomes, except for birth length (Table 5). In this study, there were no statistically significant interaction items (Additional file 1: Table S6).

According to the recorded status of passive smoking (yes or no), the distance from residence to arterial traffic $(<35 \mathrm{~m}$ or $\geq 35 \mathrm{~m}$ ), heating system (collective or selfprovided) and cooking experience during pregnancy (yes or no), we classified subjects into two groups and compared the levels of the four PAH metabolites between the groups. As shown in Table 6, we found that the concentrations of 2-OH NAP and 1-OH PYR in maternal urine samples differed between the two groups when stratified by the distance from their residence to arterial traffic. The group of subjects that resided less than $35 \mathrm{~m}$ from arterial traffic had a higher level of 2-OH NAP and 1-OH PYR compared to the group that lived more than $35 \mathrm{~m}$ away $(8.56 \mu \mathrm{g} / \mathrm{g} \mathrm{Cr}$ vs. $6.53 \mu \mathrm{g} / \mathrm{g}$ $\mathrm{Cr}$ and $2.53 \mu \mathrm{g} / \mathrm{g} \mathrm{Cr}$ vs. $2.10 \mu \mathrm{g} / \mathrm{g} \mathrm{Cr}$ ). The concentration of 1-OH PYR was higher in the group with self-provided heating than in the group with collective heating $(2.52 \mu \mathrm{g} / \mathrm{g}$ Cr vs. $2.21 \mu \mathrm{g} / \mathrm{g} \mathrm{Cr})$. We speculated that traffic pollution may contribute to the increased 2-OH NAP concentration of maternal urinary PAH metabolites. Therefore, multiple linear regression analysis was performed for subjects who lived more and less than $35 \mathrm{~m}$ away from arterial traffic (Table 7). When the analysis was performed for the lower distance group $(<35 \mathrm{~m})$, an association of 2-OH NAP with low BW and high CI was 
Table 4 Associations between four PAH metabolites and birth outcomes by multiple linear regression in different models

\begin{tabular}{|c|c|c|c|c|c|}
\hline \multirow[t]{2}{*}{ Model } & \multirow[t]{2}{*}{ Birth outcomes } & \multicolumn{4}{|l|}{$\beta(p)$} \\
\hline & & 2-OH NAP & 2-OH FLU & 9-OH PHE & 1-OH PYR \\
\hline \multirow[t]{5}{*}{ Model 1} & BW & $-73.66(0.035)$ & $-78.83(0.038)$ & $-45.04(0.172)$ & $-46.39(0.109)$ \\
\hline & $B L$ & $-0.19(0.217)$ & $0.06(0.716)$ & $0.07(0.636)$ & $0.22(0.082)$ \\
\hline & $\mathrm{BHC}$ & $-0.09(0.401)$ & $-0.08(0.503)$ & $-0.11(0.312)$ & $-0.04(0.675)$ \\
\hline & $\mathrm{Pl}$ & $-0.03(0.194)$ & $-0.08(0.004)$ & $-0.05(0.018)$ & $-0.08(0.001)$ \\
\hline & $\mathrm{Cl}$ & $2.18(0.017)$ & $2.24(0.024)$ & $1.20(0.164)$ & $1.36(0.072)$ \\
\hline \multirow[t]{5}{*}{ Model 2} & BW & $-83.14(0.009)$ & $-82.82(0.016)$ & $-51.20(0.087)$ & $-45.19(0.086)$ \\
\hline & $B L$ & $-0.20(0.180)$ & $0.06(0.710)$ & $0.06(0.681)$ & $0.24(0.055)$ \\
\hline & $\mathrm{BHC}$ & $-0.12(0.239)$ & $-0.09(0.405)$ & $-0.13(0.196)$ & $-0.04(0.681)$ \\
\hline & $\mathrm{Pl}$ & $-0.04(0.120)$ & $-0.08(0.002)$ & $-0.06(0.010)$ & $-0.08(0.001)$ \\
\hline & $\mathrm{Cl}$ & $2.38(0.005)$ & $2.31(0.012)$ & $1.34(0.095)$ & $1.32(0.061)$ \\
\hline \multirow[t]{5}{*}{ Model 3} & BW & $-71.18(0.055)$ & $-79.54(0.125)$ & $28.16(0.584)$ & $6.27(0.885)$ \\
\hline & $B L$ & $-0.32(0.069)$ & $-0.20(0.401)$ & $-0.15(0.540)$ & $0.55(0.070)$ \\
\hline & $\mathrm{BHC}$ & $-0.08(0.506)$ & $-0.05(0.771)$ & $-0.16(0.349)$ & $0.13(0.372)$ \\
\hline & PI & $-0.01(0.858)$ & $-0.02(0.531)$ & $0.04(0.294)$ & $-0.09(0.005)$ \\
\hline & $\mathrm{Cl}$ & $2.06(0.037)$ & $2.18(0.115)$ & $-1.06(0.440)$ & $0.06(0.960)$ \\
\hline \multirow[t]{5}{*}{ Model 4} & BW & $-71.83(0.053)$ & $-89.69(0.088)$ & $38.95(0.457)$ & $2.54(0.953)$ \\
\hline & $B L$ & $-0.31(0.071)$ & $-0.21(0.399)$ & $-0.14(0.567)$ & $0.55(0.080)$ \\
\hline & $\mathrm{BHC}$ & $-0.08(0.506)$ & $-0.03(0.858)$ & $-0.18(0.296)$ & $0.13(0.353)$ \\
\hline & $\mathrm{Pl}$ & $-0.01(0.831)$ & $-0.03(0.402)$ & $0.05(0.211)$ & $-0.09(0.004)$ \\
\hline & $\mathrm{Cl}$ & $2.09(0.035)$ & $2.55(0.069)$ & $-1.46(0.297)$ & $0.19(0.869)$ \\
\hline
\end{tabular}

Model 1: unadjusted for covariates

Model 2: adjusted for maternal BMI and gestational age

Model 3: adjusted for potential confounding factors (parity, maternal BMI, maternal age, gender of newborn, gestational age, eating grilled meat, passive smoking, and levels of the other three PAH metabolites)

Model 4: fully adjusted for potential confounding factors (parity, maternal BMI, maternal age, gender of newborn, gestational age, eating grilled meat, passive smoking, and levels of the other three PAH metabolites, urinary phenol, and cord blood lead)

The bold presented a $p$-value less than 0.05

shown after adjusting for parity, maternal BMI, maternal age, gender of newborn, gestational age, eating grilled meat, passive smoking, and levels of urinary phenol, cord blood lead, 2-OH FLU, 9-OH PHE, and 1-OH PYR. However, we did not reveal a similar association for subjects who lived more than $35 \mathrm{~m}$ away from arterial traffic. It is well known that automobile exhaust gases contain high levels of PAH, especially naphthalene. The present data indicated that traffic pollution may be one of the major exposure sources of naphthalene for the general population in Taiyuan city.

\section{Discussion}

We demonstrated for the first time that naphthalene had an adverse effect on birth outcomes. The results showed a significant association of 2-OH NAP level with low BW and high CI. In the present study, we evaluated this dose-response association between 2-OH NAP and birth outcomes after adjusting for levels of 2-OH FLU, 9-OH PHE, and 1-OH PYR and other potential confounders. Further, multiple linear regressions were performed to test the relationship between 2-OH NAP and birth outcomes in different models. There was a consistent positive association between 2-OH NAP and the CI. According to the possible sources of naphthalene, linear regression analysis was performed to test the association in different subsets. The results indicated that one of the major sources of naphthalene may be automobile exhaust in Taiyuan city. A previous study showed that, aside from industrial sources, traffic pollution is the second largest source of naphthalene [22]. The ratio between the traffic source and nonindustrial coal-burning source of naphthalene is 0.77 , which indicates that naphthalene is mainly released from traffic pollution, while the other three PAHs are mainly generated by nonindustrial coal-burning. Similar studies have not observed an association of prenatal 2-OH NAP with birth outcomes. The discrepancy between studies may be due to different naphthalene exposure levels. The median concentration of urinary 2-OH NAP $(6.34 \mu \mathrm{g} / \mathrm{g})$ in the present study was higher than that observed in the study by Lamichhane et al. (9.96 ng/g) [18] and Herbstman 
Table 5 Associations between all covariates and birth outcomes by multiple linear regression

\begin{tabular}{|c|c|c|c|c|c|}
\hline Variables & BW & $\mathrm{BL}$ & $\mathrm{BHC}$ & $\mathrm{Pl}$ & $\mathrm{Cl}$ \\
\hline \multicolumn{6}{|c|}{ Maternal age } \\
\hline$\beta$ & -2.43 & -0.07 & 0.01 & 0.01 & 0.09 \\
\hline$p$ & 0.695 & 0.026 & 0.588 & 0.058 & 0.593 \\
\hline \multicolumn{6}{|c|}{ Maternal BMI } \\
\hline$\beta$ & 27.52 & 0.04 & 0.07 & 0.02 & -0.62 \\
\hline$p$ & 0.001 & 0.293 & 0.005 & 0.006 & 0.002 \\
\hline \multicolumn{6}{|l|}{ Parity } \\
\hline$\beta$ & -48.49 & 0.20 & 0.12 & -0.07 & 1.80 \\
\hline$p$ & 0.393 & 0.452 & 0.509 & 0.096 & 0.235 \\
\hline \multicolumn{6}{|c|}{ Gestational age } \\
\hline$\beta$ & 20.84 & 0.06 & 0.07 & 0.01 & -0.50 \\
\hline$P$ & 0.001 & 0.001 & 0.001 & 0.001 & 0.001 \\
\hline \multicolumn{6}{|c|}{ Gender (female vs. male) } \\
\hline$\beta$ & -67.66 & 0.07 & -0.30 & -0.06 & 1.13 \\
\hline$p$ & 0.166 & 0.751 & 0.058 & 0.074 & 0.386 \\
\hline \multicolumn{6}{|c|}{ Passive smoking } \\
\hline$\beta$ & -41.20 & -0.19 & -0.17 & 0.01 & 0.14 \\
\hline$p$ & 0.402 & 0.423 & 0.285 & 0.921 & 0.913 \\
\hline \multicolumn{6}{|l|}{ 2-OH NAP } \\
\hline$\beta$ & -71.83 & -0.31 & -0.08 & -0.01 & 2.09 \\
\hline$p$ & 0.053 & 0.071 & 0.506 & 0.831 & 0.035 \\
\hline \multicolumn{6}{|c|}{ Eating grilled meat } \\
\hline$\beta$ & 8.69 & 0.19 & -0.10 & -0.02 & -0.57 \\
\hline$p$ & 0.859 & 0.400 & 0.513 & 0.524 & 0.664 \\
\hline \multicolumn{6}{|c|}{ Urinary phenol } \\
\hline$\beta$ & 8.48 & 0.11 & -0.08 & -0.01 & -0.41 \\
\hline$p$ & 0.721 & 0.310 & 0.315 & 0.442 & 0.519 \\
\hline \multicolumn{6}{|c|}{ Cord blood lead } \\
\hline$\beta$ & 77.93 & -0.10 & -0.07 & 0.09 & -2.70 \\
\hline$p$ & 0.240 & 0.750 & 0.759 & 0.071 & 0.127 \\
\hline
\end{tabular}

Adjusted for parity, maternal BMl, maternal age, gender of newborn, gestational age, eating grilled meat, passive smoking, and levels of the other three PAH metabolites, urinary phenol, and cord blood lead. The bold text indicates a $p$-value less than 0.05

et al. $(3.11 \mu \mathrm{g} / \mathrm{g})$ [36]. Jing JQ et al. [22] showed that the highest emission load among 16 PAHs was naphthalene in Taiyuan, with a $39.18 \%$ contribution rate. The PAH levels from the emission load were consistent with maternal urinary PAH metabolite levels. Researchers have reported in human studies that naphthalene has adverse effects on the neurological function of adults, causing confusion, altered sensorium, listlessness and lethargy, and vertigo [37-40]. Considering the risk of brain damage in newborns, some researchers also advocate banning the use of mothballs on a national level [41]. The $\mathrm{CI}$ can serve as a predictive index of neurodevelopment and intelligence quotient in the perinatal period [31]. The present study concluded that naphthalene has an adverse effect on CI, which was in accordance with the biological plausibility theory. We also found that 1-OH PYR was inversely associated with birth outcomes, which was consistent with a previous study [17]. We did not detect a similar association with 2-OH FLU or 9-OH PHE, which presented at a lower concentration in urine than 2-OH NAP.

The biological mechanism of naphthalene-associated adverse effects on birth outcomes remains unclear. Reviewing the related studies, we found that the possible mechanisms included the following aspects. First, naphthalene can destroy the red blood cell and induce fetus hemolytic anemia, especially when the fetus is deficient in glucose-6-phosphate dehydrogenase [2]. Lower hemoglobin can affect the supply of energy and nutrients, which are essential for normal newborn growth and development. Second, the developmental toxicity of naphthalene may contribute to its toxicity to early blastocysts. Accordingly, experimental evidence shows that naphthalene co-cultured with aroclor-induced rat hepatic S-9 fractions exhibited concentrationdependent embryo toxicity in early mouse blastocysts [42]. Third, reactive oxygen species (ROS) formation during naphthalene metabolism can influence newborn development. Naphthalene exposure can produce dosedependent decreases in cellular glutathione (GSH), adenosine triphosphate (ATP) and cell viability in rat, mouse and human hepatocytes in vitro [43]. Decreased GSH, ATP and cell viability may be suggested as contributing mechanisms in naphthalene-induced cytotoxicity in human exposed to naphthalene. Finally, DNA methylation may be one of the potential mechanisms involved in naphthalene-induced adverse effects on birth outcomes. Several studies have demonstrated that exposure to PAHs can change the methylation of specific genes and global genomic DNA methylation [44-46]. Previous studies have also revealed that the presence of maternal 2-OH NAP is associated with lower methylation levels within the Alu and LINE-1 [47].

We recognize the following limitations in this study. First, there is no external exposure information, which can reflect the level of naphthalene in the environment. Due to the characteristics of naphthalene and complicated detection methods, we did not measure naphthalene concentrations in air. However, PAH metabolites are a validated internal exposure biomarker, and the level of 2-OH NAP can reveal the actual level of naphthalene in the body [48]. Second, biological samples were collected at a single time point (the third trimester), which does not reveal the exposure during the entire pregnancy. Furthermore, the half-life estimate ranged from 2.5-6.1 h for PAH metabolites [49]. We must admit that collecting a single spot urine sample is 
Table 6 Concentrations of PAH metabolites stratified by possible sources of PAH ( $\mu \mathrm{g} / \mathrm{g} \mathrm{Cr}$ )

\begin{tabular}{|c|c|c|c|c|}
\hline Variables & 2-OH NAP & 2-OH FLU & 9-OH PHE & 1-OH PYR \\
\hline \multicolumn{5}{|l|}{ Passive smoking } \\
\hline Yes & $7.38(6.10,8.67)$ & $4.14(3.59,4.69)$ & $3.36(2.84,3.87)$ & $2.02(1.73,2.32)$ \\
\hline No & $7.24(6.39,8.08)$ & $4.20(3.70,4.70)$ & $3.63(3.15,4.11)$ & $2.44(2.10,2.77)$ \\
\hline$p$ & 0.770 & 0.679 & 0.792 & 0.435 \\
\hline \multicolumn{5}{|c|}{ Distance from arterial traffic } \\
\hline$<35 \mathrm{~m}$ & $8.56(7.05,10.06)$ & $4.44(3.68,5.21)$ & $4.01(3.29,4.74)$ & $2.53(2.07,2.99)$ \\
\hline$\geq 35 \mathrm{~m}$ & $6.53(5.94,7.12)$ & $4.04(3.66,4.42)$ & $3.24(2.87,3.61)$ & $2.10(1.82,2.37)$ \\
\hline$p$ & 0.041 & 0.768 & 0.095 & 0.035 \\
\hline \multicolumn{5}{|l|}{ Heating type } \\
\hline Collective & $7.54(6.71,8.38)$ & $4.07(3.61,4.53)$ & $3.51(3.07,3.96)$ & $2.21(1.91,2.51)$ \\
\hline Self-provided & $6.68(5.46,7.90)$ & $4.51(3.89,5.14)$ & $3.60(3.05,4.14)$ & $2.52(2.15,2.90)$ \\
\hline$P$ & 0.239 & 0.086 & 0.366 & 0.019 \\
\hline \multicolumn{5}{|c|}{ Cooking during pregnant period } \\
\hline Yes & $7.54(6.37,8.71)$ & $3.86(3.39,4.33)$ & $3.25(2.82,3.68)$ & $2.08(1.73,2.42)$ \\
\hline No & $7.25(6.38,8.11)$ & $4.48(3.91,5.06)$ & $3.79(3.23,4.35)$ & $2.46(2.12,2.81)$ \\
\hline$P$ & 0.526 & 0.275 & 0.499 & 0.222 \\
\hline
\end{tabular}

The table presents the mean and $95 \%$ confidence interval. The bold presented a $p$-value less than 0.05

a flaw of our design. Single spot urine sample measurement may not reflect the effects of long-term exposure to $\mathrm{PAH}$, given the short half-life of $\mathrm{PAH}$ metabolites (several hours to days). Thus, multiple urine sample measurements should be used in future studies to evaluate the individual long-term exposure to environmental PAH. Accumulative epidemiologic studies also use single-point urinary PAH metabolites as internal exposure biomarkers, and random single-point PAH metabolites can be used to evaluate PAH exposure levels $[47,50]$. Third, none of the birth outcomes considered the population standard for expected growth, which was mainly because the features of recruited subjects were not suitable for considering the clinical relevance in our study. The majority of newborn

Table 7 Multiple linear regression model testing associations of 2-OH NAP with birth outcomes in subsets

\begin{tabular}{|c|c|c|c|c|c|}
\hline & BW & $B L$ & $\mathrm{BHC}$ & $\mathrm{Pl}$ & $\mathrm{Cl}$ \\
\hline \multicolumn{6}{|c|}{ Arterial traffic $\geq 35 \mathrm{~m}(n=113)$} \\
\hline \multicolumn{6}{|c|}{$2-\mathrm{OH} \mathrm{NAP}$} \\
\hline$\beta$ & -6.85 & -0.07 & -0.16 & 0.01 & -0.07 \\
\hline$p$ & 0.904 & 0.785 & 0.361 & 0.934 & 0.963 \\
\hline \multicolumn{6}{|c|}{ Arterial traffic $<35 \mathrm{~m}(n=150)$} \\
\hline \multicolumn{6}{|c|}{ 2-OH NAP } \\
\hline$\beta$ & -112.56 & -0.46 & 0.01 & -0.12 & 3.50 \\
\hline$p$ & 0.035 & 0.064 & 0.999 & 0.753 & 0.016 \\
\hline
\end{tabular}

Adjusted for parity, maternal BMI, maternal age, gender of newborn, gestational age, eating grilled meat, passive smoking, and levels of the other three PAH metabolites, urinary phenol, and cord blood lead; the bold text indicates $p<0.05$ birth outcomes were in the normal range (98.5\%), and there were only 4 low-birth-weight infants and premature infants (1.5\%). If we use the population standard as a cutoff point, the models will be unstable and unrealized. Accumulative studies show that low BW (not clinically significant) still increases the risk of suffering from disease in adulthood $[13,51]$. The purpose of this study was to investigate the relationship between PAH metabolites and birth outcomes. Our conclusion may be useful for environmental policy making. Finally, the sample size was relatively small in this study. Power analysis showed that the power of this sample size was 0.7 (BW) and $0.8(\mathrm{CI})$ after adjusting for covariates (Additional file 1: Figure S4 and Figure S5). For BW analysis, when the 2-OH NAP level increased, BW was significantly decreased in different models after adjusting for potential confounders. This result provided some clues about the effect of naphthalene on BW. For the CI, the power of sample size was enough, and the conclusion that $2-\mathrm{OH}$ NAP was adversely related to a high CI was reliable. Some variables, e.g., passive smoking and the distance from the residence to the arterial road, were solely obtained from self-reported questionnaires. An internal exposure marker, such as cotinine in saliva, can provide accurate information about passive smoking. The geoinformatics analysis can obtain more accurate distance information. However, we do not believe that there is any reason for the study participants to consistently overor underestimate the passive smoking and distance information. There may be random errors that are against our study hypothesis. These limitations are 
offset by the comprehensiveness of the analyses, which include the use of multiple models and proper adjustment for potential confounding variables.

\section{Conclusion}

In summary, the present data documents that naphthalene exposure is associated with adverse effects on BW and CI. Therefore, naphthalene exposure from traffic and fossil fuel burning should be decreased during pregnancy to improve the health of newborns.

\section{Additional file}

Additional file 1: Additional file of maternal urinary 2-hydroxynaphthalene and birth outcomes in Taiyuan, China. (DOC $182 \mathrm{~kb}$ )

\section{Abbreviations}

1-OH PYR: 1-hydroxypyrene; 2-OH FLU: 2-hydroxyfluorene; 2-OH NAP: 2hydroxynaphthalene; 9-OH PHE: 9-hydroxyphenanthrene; BHC: Birth head circumference; BL: Birth length; BMI: Body mass index; BW: Birth weight; Cl: Cephalization index; HPLC-FLD: High performance liquid chromatography with fluorescence detector; IQR: Median and interquartile range; LOD: Limit of detection; PAH: Polycyclic aromatic hydrocarbon; PI: Ponderal index; $\Sigma \mathrm{OH}$ PAH: The sum of four metabolites of PAH; SD: Standard deviation

\section{Acknowledgments}

Not applicable.

\section{Funding}

This study was supported by the National Natural Science Foundation of China (81673143, 81072279 and 30800899), the Shanxi Province Natural Science Foundation of China (2015011128, 2010021034-3), the Shanxi Scholarship Council of China (2016-057), the Smith Family Foundation (G-1610-56442), and the Rockefeller Brothers Foundation (17-101).

\section{Availability of data and materials}

Please contact the corresponding author for any data request.

\section{Authors' contributions}

Study conceptualization and design: JN, DT, QN, FP, and JL; Data collection: ZY, LC, and JL; Data cleaning and discrepancy checks: JL and LC; Analysis of biological samples: YD, YL, and LD; Analytic strategy: JN, DT, FP, and QN; Analysis and interpretation of data: $J L$ and $L C$; Manuscript preparation: $L$ and $J \mathrm{~N}$; Final approval of manuscript: JN, JL, LC, YD, YL, ZY, LD, QN, FP, and DT. All authors read and approved the final manuscript.

\section{Ethics approval and consent to participate}

The study is reviewed and approved by the Research Ethics Committee of Shanxi Medical University (approval no. 2013096). Signed informed consent was obtained from all participants.

\section{Consent for publication}

The manuscript is reviewed and approved by all authors.

\section{Competing interests}

All authors declare that they have no competing financial or nonfinancial interests with regard to the research described.

\section{Publisher's Note}

Springer Nature remains neutral with regard to jurisdictional claims in published maps and institutional affiliations.

\section{Author details}

'Department of Occupational and Environmental Health, School of Public Health, Shanxi Medical University, Xinjiannan Road 56, Taiyuan 030001, China.
${ }^{2}$ Department of Environmental Health Sciences, Mailman School of Public Health, Columbia University, 722W. 168th Street, New York, NY 10032, USA.

Received: 9 June 2018 Accepted: 4 December 2018

Published online: 20 December 2018

References

1. Nethery E, Wheeler AJ, Fisher M, Sjodin A, Li Z, Romanoff LC, Foster W, Arbuckle TE. Urinary polycyclic aromatic hydrocarbons as a biomarker of exposure to PAHs in air: a pilot study among pregnant women. J. Expo. Sci. Environ. Epidemiol. 2012;22(1):70-81.

2. Santucci K, Shah B. Association of naphthalene with acute hemolytic anemia. Acad Emerg Med Off J Soc Acad Emerg Med. 2000;7(1):42-7.

3. Zinkham WH, Childs B. A defect of glutathione metabolism in erythrocytes from patients with a naphthalene-induced hemolytic anemia. Pediatrics. 1958;22(3):461-71.

4. Elmasri H, Mumtaz M, Todd GD, Mcclure PR. Toxicological profile for naphthalene, 1-methylnaphthalene, and 2-methylnaphthalene. Atsdr Toxicological Profile. 2005;4(4):206-7.

5. Rappaport SM, Waidyanatha S, Serdar B. Naphthalene and its biomarkers as measures of occupational exposure to polycyclic aromatic hydrocarbons. J Environ Monit. 2004:6(5):413-6.

6. Economic and trade office of the state council: Circular of the economic and trade office of the state council and the ministry of health concerning the suspension of the production and sale of naphthalene pills for the promotion of the use of camphor products (GJM(1993) no. 64). https:// www.lawxp.com/statute/s568390.html Accessed 16 Feb 1993.

7. Barr DB, Bishop A, Needham LL. Concentrations of xenobiotic chemicals in the maternal-fetal unit. Reproductive toxicology (Elmsford, NY). 2007;23(3): 260-6.

8. Makri A, Goveia M, Balbus J, Parkin R. Children's susceptibility to chemicals: a review by developmental stage. J Toxicol Environ Health B Crit Rev. 2004; 7(6):417-35

9. Al-Saleh I, Alsabbahen A, Shinwari N, Billedo G, Mashhour A, Al-Sarraj Y, Mohamed Gel D, Rabbah A. Polycyclic aromatic hydrocarbons (PAHs) as determinants of various anthropometric measures of birth outcome. Sci Total Environ. 2013:444:565-78

10. Singh VK, Singh J, Anand M, Kumar P, Patel DK, Krishna Reddy MM, Javed Siddiqui MK. Comparison of polycyclic aromatic hydrocarbon levels in placental tissues of Indian women with full- and preterm deliveries. Int J Hyg Environ Health. 2008;211(5-6):639-47.

11. Crusell M, Damm P, Hansen T, Pedersen O, Glumer C, Vaag A, Lauenborg J. Ponderal index at birth associates with later risk of gestational diabetes mellitus. Arch Gynecol Obstet. 2017:296(2):249-56.

12. Rogers CLaJM. Embryonic and fetal programming of physiological disorders in adulthood. Birth Defects Research. 2003;72:300-12.

13. Barker COaDJP. Fetal, infant, and childhood growth are predictors of coronary heart disease, diabetes and hypertension in adult men and women. Environ Health Perspect. 2000;108:545-53.

14. Linsell L, Malouf R, Morris J, Kurinczuk JJ, Marlow N. Prognostic factors for poor cognitive development in children born very preterm or with very low birth weight. JAMA Pediatr. 2015;169(12):1162.

15. Shenkin SD, Starr JM, Deary IJ. Birth weight and cognitive ability in childhood: a systematic review. Psychol Bull. 2004;130(6):989-1013.

16. Polanska K, Dettbarn G, Jurewicz J, Sobala W, Magnus P, Seidel A, Hanke W. Effect of prenatal polycyclic aromatic hydrocarbons exposure on birth outcomes: the polish mother and child cohort study. Biomed Res Int. 2014; 2014:1-10.

17. Suzuki Y, Niwa M, Yoshinaga J, Mizumoto Y, Serizawa S, Shiraishi H. Prenatal exposure to phthalate esters and PAHs and birth outcomes. Environ Int 2010;36(7):699-704

18. Lamichhane DK, Leem JH, Kim HC, Lee JY, Park MS, Jung DY, Ko JK, Ha M, Kim Y, Hong YC, et al. Impact of prenatal exposure to polycyclic aromatic hydrocarbons from maternal diet on birth outcomes: a birth cohort study in Korea. Public Health Nutr. 2016;19(14):2562-71.

19. Shopp GM, White KL Jr, Holsapple MP, Barnes DW, Duke SS, Anderson AC, Condie LW Jr, Hayes JR, Borzelleca JF. Naphthalene toxicity in CD-1 mice: general toxicology and immunotoxicology. Fundam Appl Toxicol. 1984;4(3 Pt 1):406-19.

20. Plasterer MR, Bradshaw WS, Booth GM, Carter MW, Schuler RL, Hardin BD. Developmental toxicity of nine selected compounds following prenatal 
exposure in the mouse: naphthalene, p-nitrophenol, sodium selenite, dimethyl phthalate, ethylenethiourea, and four glycol ether derivatives. J Toxicol Environ Health. 1985;15(1):25-38.

21. Xia Z, Duan X, Tao S, Qiu W, Liu D, Wang Y, Wei S, Wang B, Jiang Q, Lu B, et al. Pollution level, inhalation exposure and lung cancer risk of ambient atmospheric polycyclic aromatic hydrocarbons (PAHs) in Taiyuan, China. Environ Pollut. 2013;173:150-6.

22. Jing JQ, Yu LY, Xin HX, Bin LU, Shu T, Rong W. Estimation of annual emission and distribution characteristics of polycyclic aromatic hydrocarbons(PAHs) in Taiyuan. China Environ Sci. 2013;33(1):14-20.

23. Yang P, Zhou B, Cao WC, Wang YX, Huang Z, Li J, Lu WQ, Zeng Q. Prenata exposure to drinking water disinfection by-products and DNA methylation in cord blood. Sci Total Environ. 2017:586:313-8.

24. State Bureau of Technical Supervision and Ministry of Construction, PRC: Code for transport planning on urban road (GB 50220-95). https://wenku. baidu.com/view/627ccae587c24028905fc3dd.html?from=search. Accessed 14 Jan 1995.

25. Yu LI, Dong DM, Xiao-Jun LV, Yong-Zheng LU: Pollution characteristics of lead in soils beside road 102. 2004.

26. Kim H, Cho SH, Kang JW, Kim YD, Nan HM, Lee CH, Lee H, Kawamoto T. Urinary 1-hydroxypyrene and 2-naphthol concentrations in male Koreans. Int Arch Occup Environ Health. 2001;74:59-62.

27. Jacob J, Seidel A. Biomonitoring of polycyclic aromatic hydrocarbons in human urine. J Chromatogr. 2002;778:31-47.

28. Ministry of Health of the People's Republic of China: Urine-Determination of phenol-Gas chromatographic method-II FFAP column WS/T 50-1996. https://www.wiki8.com/WS.2FT+50.E2.80.941996 +niaozhongbenfendeqixiangsepucedingfangfa+.EF.BC.88er.EF.BC. 89FFAPzhufa_148685/. Accessed 14 Oct 1996.

29. Yan J, Gao Z, Wang J, Ma W, Ying X, Zhou C, Yan C. Family environmental and dietary implications for low-level prenatal lead exposure in Wujiang City, China. Environ Sci Pollut Res Int. 2018;25(13):12780-7.

30. Davies DP. Size at birth and growth in the first year of life of babies who are overweight and underweight at birth. Proc Nutr Soc. 1980;39(1):25-33.

31. F-VA LY, Geva R, Eshel R, Toledano-Alhadef $H$, Rotstein $M$, et al. Neurodevelopmental outcome of children with intrauterine growth retardation: a longitudinal, 10-year prospective study. J Child Neurol. 2007;22:580-7.

32. Harel S, Tomer A, Barak Y, Binderman I, Yavin E. The cephalization index: a screening device for brain maturity and vulnerability in normal and intrauterine growth retarded newborns. Brain Dev. 1985;7(6):580-4.

33. Montgomery DC, Peck EA. Introduction to linear regression analysis: Wiley; 1982. https://doi.org/10.1080/02664763.2013.816069.

34. Stewart GW. Collinearity and least squares regression. Stat Sci. 1987;2(1):68-84.

35. O'Brien RM. A caution regarding rules of thumb for variance inflation factors. Qual Quant. 2007:41(5):673-90.

36. Herbstman JB, Tang D, Zhu D, Qu L, Sjödin A, Li Z, Camann D, Perera FP. Prenatal exposure to polycyclic aromatic hydrocarbons, benzo[a]pyreneDNA adduct, and genomic DNA methylation in cord blood. Environ Health Perspect. 2012;120(5):733-8.

37. Ojwang PJ, Ahmed-Jushuf $I H$, Abdullah MS. Naphthalene poisoning following ingestion of moth balls: case report. East Afr Med J. 1985;62(1):71-3.

38. Gupta R, Singhal PC, Muthusethupathy MA, Malik AK, Chugh KS. Cerebra oedema and renal failure following naphthalene poisoning. J Assoc Physicians India. 1979:27(4):347-8.

39. Chusid E, Fried CT. Acute hemolytic anemia due to naphthalene ingestion. AMA Am J Dis Child. 1955;89(5):612-4.

40. Gidron E, Leurer J. Naphthalene poisoning. Lancet (London, England). 1956; 270(6910):228-31.

41. Tarnow-Mordi WO, Evans NJ, Lui K, Darlow B. Risk of brain damage in babies from naphthalene in mothballs: call to consider a national ban. Med J Aust. 2011;194(3):150

42. Poorni lyer JEMaTRI. Role of biotransformation in the in vitro preimplantation embryotoxicity of naphthalene. Toxicology. 1991;66:257-70.

43. Kedderis GL, Shepard KG, Recio L. Cytotoxicity of naphthalene toward cells from target and non-target organs in vitro. Chem Biol Interact. 2014;209:85-95.

44. Lee J, Kalia V, Perera F, Herbstman J, Li T, Nie J, Qu LR, Yu J, Tang D. Prenatal airborne polycyclic aromatic hydrocarbon exposure, LINE1 methylation and child development in a Chinese cohort. Environ Int. 2017;99:315-20.

45. Alhamdow A, Lindh C, Hagberg J, Graff $P$, Westberg H, Krais AM, Albin M, Gustavsson P, Tinnerberg H, Broberg K. DNA-methylation of the cancer- related genes F2RL3 and AHRR is associated with occupational exposure to polycyclic aromatic hydrocarbons. Carcinogenesis. 2018;39(7):869-78.

46. Yang J, Liu Y, Zhang H, Zhang H, Wang W, Fan Y. Urinary 1-hydroxypyrene and smoking are determinants of LINE-1 and AhRR promoter methylation in coke oven workers. Mutat Res. 2018;826:33-40.

47. Yang P, Gong YJ, Cao WC, Wang RX, Wang YX, Liu C, Chen YJ, Huang LL, Ai $\mathrm{SH}$, Lu WQ, et al. Prenatal urinary polycyclic aromatic hydrocarbon metabolites, global DNA methylation in cord blood, and birth outcomes: a cohort study in China. Environ Pollut. 2017:234:396-405.

48. Desai G, Chu L, Guo Y, Myneni AA, Mu L. Biomarkers used in studying air pollution exposure during pregnancy and perinatal outcomes: a review. Biomarkers. 2017;22(6):489-501.

49. Li Z, Romanoff L, Bartell S, Pittman EN, Trinidad DA, McClean M, Webster TF, Sjodin A. Excretion profiles and half-lives of ten urinary polycyclic aromatic hydrocarbon metabolites after dietary exposure. Chem Res Toxicol. 2012; 25(7):1452-61.

50. Yang J, Zhang H, Zhang H, Wang W, Liu Y, Fan Y. Smoking modify the effects of polycyclic aromatic hydrocarbons exposure on oxidative damage to DNA in coke oven workers. Int Arch Occup Environ Health. 2017;90(5): 423-31.

51. Streja E, Miller JE, Wu C, Bech BH, Pedersen LH, Schendel DE, Uldall P, Olsen J. Disproportionate fetal growth and the risk for congenital cerebral palsy in singleton births. PLoS One. 2015;10(5):e0126743.
Ready to submit your research? Choose BMC and benefit from:

- fast, convenient online submission

- thorough peer review by experienced researchers in your field

- rapid publication on acceptance

- support for research data, including large and complex data types

- gold Open Access which fosters wider collaboration and increased citations

- maximum visibility for your research: over $100 \mathrm{M}$ website views per year

At $\mathrm{BMC}$, research is always in progress.

Learn more biomedcentral.com/submissions 